\title{
The Biomechanical Performance Investigation of L4-L5 Lumbar Segment by Finite Element Method
}

\author{
Emre Sengul ${ }^{1}$, Ramazan Ozmen $^{2}$, Teyfik Demir ${ }^{3}$ \\ ${ }^{1}$ Roketsan Inc., \\ Elmadağ, Ankara, Turkey \\ emre.sengul@roketsan.com.tr; ramazanozmen@karabuk.edu.tr \\ ${ }^{2}$ Karabük University, Mechanical Engineering Department, \\ Merkez, Karabük, Turkey \\ ${ }^{3}$ TOBB ETU, Mechanical Engineering Department, \\ Çankaya, Ankara, Turkey \\ t.demir@etu.edu.tr
}

\begin{abstract}
The finite element (FE) method is one of the strong and productive tools in understanding the biomechanics of human lumbar spine. Therefore, the aim of this study is to create a proper three-dimensional FE model to investigate the biomechanics of a human lumbar spine segment in order to provide a better understanding for surgery and biomechanical engineering. It is known that there are material and geometric differences between human lumbar spines. Hence a proper FE model with a fine set of geometry and material properties is required to make accurate and correct predictions. For this purpose, L4-L5 lumbar spine segment was modelled with an intervertebral disc by using different material properties in the literature. The geometric data of the investigated lumbar segment was obtained from a computed tomography image of a healthy human spine. In this model, annulus fibers were modelled with membrane rebar layers, and vertebrae bones were modelled without cancellous section. Thus, the solving time is reduced by decreasing the element number of the FE model. The developed L4-L5 spinal segment model was exposed to different loading conditions such as flexion, extension, lateral bending and axial rotation. In addition, L4-L5 lumbar spine segment model was validated according to the results of experiments and computations in the literature. The consistency of simulation results with the experimental and numerical data contained in the literature were stated in this study. The developed FE model has a potential to be used in future works about surgery and biomechanical simulations of human lumbar spinal segments.
\end{abstract}

Keywords: biomechanics; lumbar spine; L4-L5 segment; finite element method; intervertebral disc.

\section{Introduction}

Performing a numerical simulation of a human lumbar spine segment is complicated due to complex geometry and various material properties of the spine. Carrying out an experimental verification on a living system is also difficult [1]. The FE method is a significant alternative for understanding the biomechanics of human lumbar spine. In addition, FE analysis has lower cost and higher efficiency compared with in vivo and in vitro experimental tests. Besides, FE models provide repeatable and modifiable analyses with multiple cases and iterations possible. There are a lot of studies using FE method in order to shed light on concerns about lumbar spine. One of them is Hassan et al.'s study [2], that they investigated the biomechanical parameters of lumbar segment by FE method in order to predict facet joint loading, intradiscal pressure, and stresses in interspinous (ISL) and capsular (CL) ligaments by comparing their results with in-vitro studies. They stated that their study has a potential contribution on solving degeneration associated problems of lumbar spine. Another study, performed by Alapan et al. [3], aimed to analyse the effects of various ligament failures, loading levels, and loading directions on the location of instantaneous center of rotation of L4-L5 lumbar segment. By this study, they demonstrated that, different scenarios in working conditions of the lumbar spine can easily be simulated by a FE model. In addition, the study of Tsouknidas et al. [4] assessed the mechanical response of a lumbar spine segment under complex loads while in the study of Lodygowski et al. [1] they formed a nonlinear FE model of the lumbar spine segment with a different intervertebral disc structure unlike other studies. All these investigations indicated that each study tried to bring a different and proper perspective like this study. By the way, the aim of this study is to create a proper three- 
dimensional FE model to investigate the biomechanics of a human lumbar spine segment in order to provide a better understanding for surgery and biomechanical engineering.

\section{Method}

\subsection{FE Model Development}

A healthy full vertebrae CT image data was taken from TOBB ETU data and was processed in MIMICS software for having a proper spine model. Then, lumbar vertebrae section (contains 13408 polygon surfaces) was separated from the whole model by using CATIA 3D CAD modelling software. During generation of cortical shell sections, Spaceclaim (ANSYS 2019) was used for surface offsetting and Geomagic Design X was used for converting stereolithography (stl) files to a proper file formats for meshing operations. Moreover, the L4-L5 lumbar vertebrae and the vertebral discs between them were created as 3D solid models. Afterwards, the intersection regions of the contact faces between lumbar vertebrae models were corrected and the 3D models are scaled up to real dimensions. Then, the analysis model whose illustration is shown in Figure 1 was generated and meshed in Abaqus 2017 with all components. In this model, annulus fibers were modelled with 6 membrane layers [1,4] which have $0.12 \mathrm{~mm}$ mean thickness [5] and contain rebars [6]. In addition, vertebrae bones were modelled without cancellous section because it doesn't have much effect on biomechanical response. By the way, the study of Kumerasan et al. showed that the effect of cancellous bone was less on biomechanics of the lumbar spine [7]. Thus, the solving time was reduced by decreasing the number of elements in the FE model. The material properties of cortical bone which is transversely isotropic and other material properties except for cancellous bone were taken from Tsouknidas et al.'s study [3]. Ligament material properties were obtained from the results of Schmidt's tests indicated in Naserkhaki et al.'s study [8]. All material properties used in the FE model are given in Table 1.

Table 1: Material properties used in the FE model.

\begin{tabular}{|l|c|c|c|}
\hline $\begin{array}{l}\text { Material } \\
\text { Type }\end{array}$ & $\begin{array}{c}\text { Young Modulus } \\
(\mathrm{MPa})\end{array}$ & $\begin{array}{c}\text { Poisson } \\
\text { Ratio }\end{array}$ & $\begin{array}{c}\text { Elements } \\
\text { (FEM) }\end{array}$ \\
\hline $\begin{array}{l}\text { Cortical } \\
\text { Bone }\end{array}$ & $\begin{array}{c}\mathrm{E}_{\mathrm{xx}}=11300 \\
\mathrm{E}_{\mathrm{yy}}=11300 \\
\mathrm{E}_{\mathrm{zz}}=11300 \\
\mathrm{G}_{\mathrm{xy}}=3800 \\
\mathrm{G}_{\mathrm{yz}}=5400\end{array}$ & $\begin{array}{c}\mathrm{v}_{\mathrm{xy}}=0.484 \\
\mathrm{v}_{\mathrm{yz}}=0.203 \\
\mathrm{v}_{\mathrm{xz}}=0.203\end{array}$ & $\mathrm{~S} 3$ \\
\hline Endplate & 23.8 & $\mathrm{v}=0.4$ & $\mathrm{C} 3 \mathrm{D} 8 \mathrm{R}$ \\
\hline $\begin{array}{l}\text { Nucleus } \\
\text { Pulposus }\end{array}$ & 0.2 & $\mathrm{v}=0.4999$ & $\mathrm{C} 3 \mathrm{D} 8 \mathrm{R}$ \\
\hline $\begin{array}{l}\text { Annulus } \\
\text { Ground } \\
\text { Substance }\end{array}$ & 4.2 & $\mathrm{v}=0.45$ & $\mathrm{C} 3 \mathrm{D} 8 \mathrm{R}$ \\
\hline $\begin{array}{l}\text { Annulus } \\
\text { Fibrosus } \\
\text { Layers }\end{array}$ & 4.2 & $\mathrm{v}=0.45$ & M3D4R \\
\hline $\begin{array}{l}\text { Fibers of } \\
\text { Layers }\end{array}$ & $\begin{array}{l}550 / 495 / 440 / \\
420 / 385 / 360\end{array}$ & $\mathrm{v}=0.45$ & Rebar \\
\hline Ligaments & $\begin{array}{c}\text { Nonlinear stress- } \\
\text { strain curves }\end{array}$ & - & Connectors \\
\hline
\end{tabular}

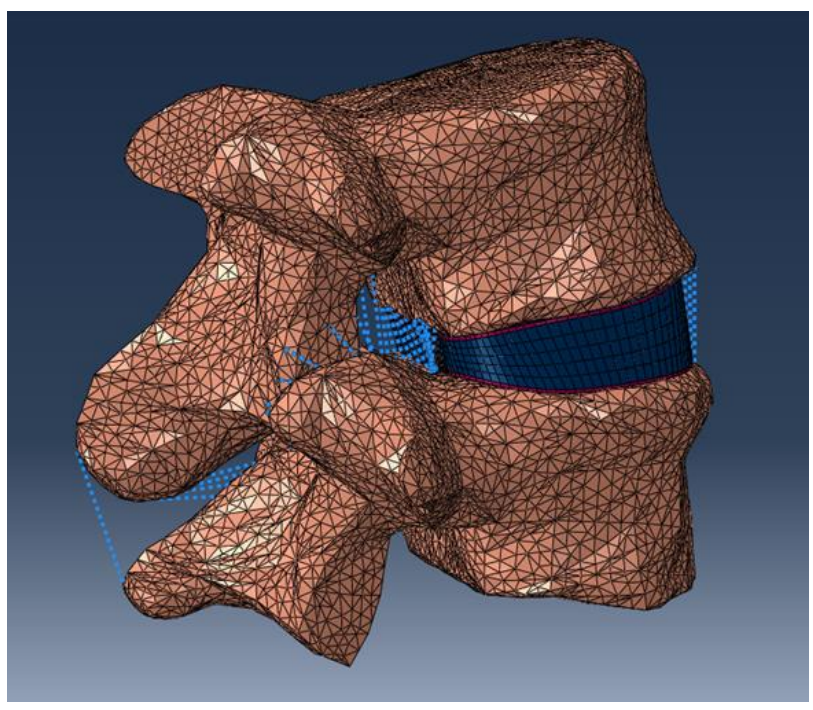

Fig. 1: L4-L5 FE model of the current study. 


\subsection{Boundary and Loading Conditions}

The developed L4-L5 spinal segment model was exposed to different loading conditions including flexion, extension, lateral bending and axial rotation. When biomechanical studies were examined, it was seen that the maximum rotation angles of the L4-L5 spine segment can be achieved by applying an approximately $12.5 \mathrm{Nm}$ torque. To perform these motions a $12.5 \mathrm{Nm}$ moment load was applied to the FE model by a defined reference point on the top surface of L4 vertebrae. Besides, the inferior endplate nodes of the L5 vertebrae were constrained in all directions. Thus, all values are obtained from initial position to final positions of related motions. Then, the required values of the present study become available to compare with $10 \mathrm{Nm}$ and $7.5 \mathrm{Nm}$ pure moment in-vitro applications in the literature.

\section{Results}

The mobility of L4-L5 lumbar spine segment model was validated according to the results of experiments and computations in the literature. The consistency of simulation results with the experimental and numerical data in the literature were stated in this study. When a $7.5 \mathrm{Nm}$ moment is applied to the L4 vertebra, the rotation angles were obtained as $7^{\circ}, 4.8^{\circ}, 7.5^{\circ}$ and $2.7^{\circ}$ for the extension, flexion, lateral bending and axial rotation motions, respectively. Besides, by applying a $10 \mathrm{Nm}$ moment load to the L4 vertebra, the rotations were obtained as $9^{\circ}, 6^{\circ}, 10^{\circ}$ and $3.5^{\circ}$ for the extension, flexion, lateral bending and axial rotation motions, respectively. The results of this study were consistent with the test results of Heuer et al. especially in the flexion, extension and axial rotation motions up to $10 \mathrm{Nm}$ moment load [8]. The findings of this study were also compared with the studies of Schilling et al., Yamamoto et al. and Erbulut et al. [6] and similar results were obtained. In the study of Schilling et al., the rotation values are obtained as $5.62 \pm 2.17^{\circ}$ in extension, $3.32 \pm 1.12^{\circ}$ in flexion, $7.76 \pm 1.85^{\circ}$ in lateral bending and $5.16 \pm 1.30^{\circ}$ in axial rotation by applying a $7.5 \mathrm{Nm}$ moment load. However, by applying a $10 \mathrm{Nm}$ moment load, Yamamoto et al. achieved rotation angles as $8.9 \pm 0.7^{\circ}$ in extension, $5.8 \pm$ $0.4^{\circ}$ in flexion, $5.9 \pm 0.5^{\circ}$ in lateral bending (right) and $2.7 \pm 0.5^{\circ}$ in axial rotation (right), while Erbulut et al. obtained these rotations as $5.5^{\circ}, 3.5^{\circ}, 7.3^{\circ}$ and $4.0^{\circ}$ in the extension, flexion, lateral bending and axial rotation (right) motions, respectively [6]. In Figure 2, the red dots with error bars represent in-vitro study results of Heuer et al., whereas the coloured continuous lines represent the present study. These coloured continues lines are obtained by applying $12.5 \mathrm{Nm}$ from initial position to final positions of the related motions. Then, the values can be determined from these lines at 7.5 $\mathrm{Nm}$ and $10 \mathrm{Nm}$ in order to compare this study with the other three studies in the literature is given in Table 2. These studies belong to Schilling et al., Yamamoto et al., Erbulut et al. [6], and represented in Table 2.

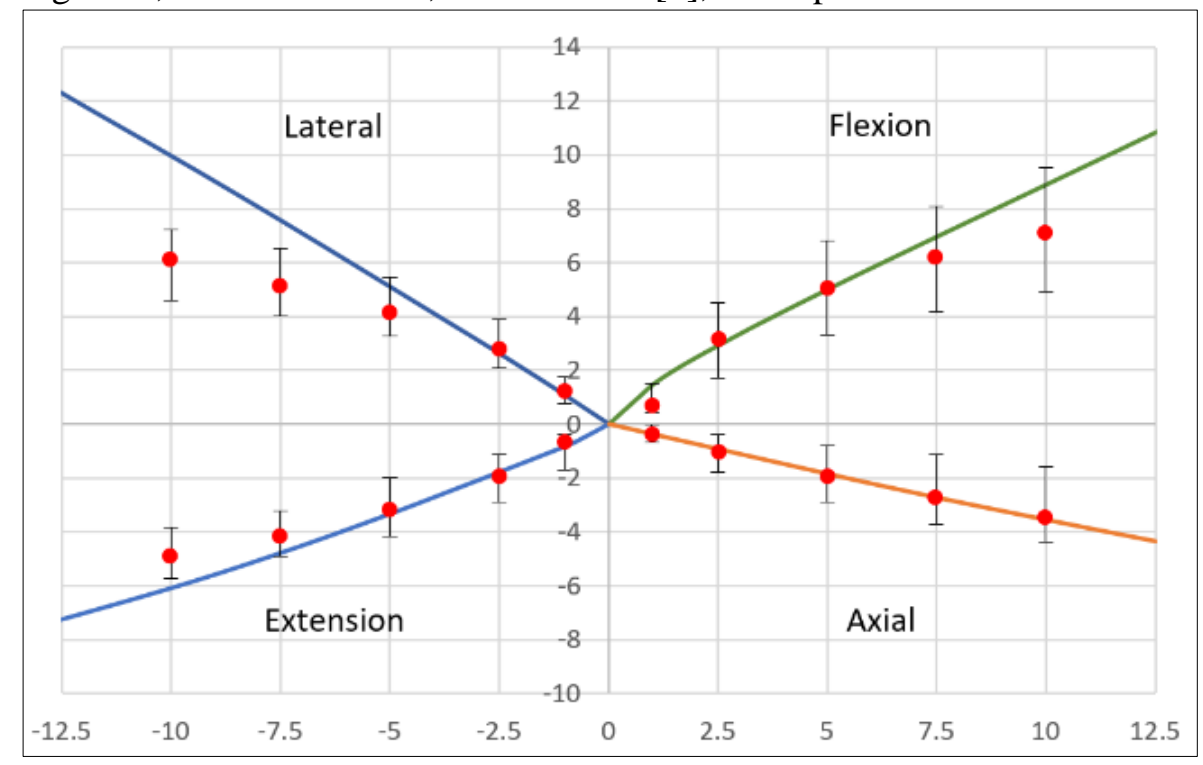

Fig. 2: The graph of the biomechanical behaviours of L4-L5 lumbar vertebra segment. (horizontal axis belongs to the moment $(\mathrm{Nm})$ and vertical axis belongs to the angle (deg)). 
Table 2: Comparison of the simulation results with the experimental and numerical data in the literature.

\begin{tabular}{|c|c|c|c|c|c|}
\hline Studies & $\begin{array}{c}\text { Pure } \\
\text { Moment } \\
(\mathrm{Nm})\end{array}$ & Flexion & Extension & Lateral & Axial \\
\hline Schilling et al. [6] & 7.5 & $5.62 \pm 2.17$ & $3.32 \pm 1.12$ & $7.76 \pm 1.85$ & $5.16 \pm 1.30$ \\
\hline Yamamoto et al. [6] & 10 & $8.9 \pm 0.7$ & $5.8 \pm 0.4$ & $(\mathrm{rt}) 5.9 \pm 0.5$ & $(\mathrm{rt}) 2.7 \pm 0.5$ \\
\hline Erbulut et al. [6] & 10 & 5.5 & 3.5 & $(\mathrm{rt}) 7.3$ & $(\mathrm{rt}) 4.0$ \\
\hline Current Study & 7.5 & 7 & 4.8 & 7.5 & 2.7 \\
\cline { 2 - 6 } & 10 & 9 & 6 & 10 & 3.5 \\
\hline
\end{tabular}

\section{Conclusion}

This study aims to create a proper three-dimensional FE model to investigate the biomechanics of a human lumbar spine segment in order to provide better understanding of it for surgery and biomechanical engineering. In addition, a different perspective is presented with the FE model structure used in this study. Besides, the solving time is reduced by the simplifications of vertebrae and intervertebral disc in the FE model. Moreover, the consistency of the results indicates that the structure can be adapted to L1-L5 or L1-S1 lumbar spine models. Thus, the developed FE model has a potential to be used in future works about surgery and biomechanical simulations of human lumbar spinal segments.

\section{References}

[1] T. Lodygowski, W. Kąkol, M. Wierszycki, and M. Ogurkowska, "Three-dimensional nonlinear finite element model of lumbar intervertebral disc," Acta of Bioengineering and Biomechanics., vol. 7, no. 2, 2005.

[2] C. R. Hassan, D. Erbulut, "Load Sharing in L4-L5 Spinal Motion Segment Using an Asymmetrical Finite Element Model," in Proceedings of the International Conference on Biomedical Engineering and Systems, Prague, Czech Republic, 2014, vol. 71.

[3] Y. Alapan, C. Demir, T. Kaner, R. Guclu, S. Inceoglu "Instantaneous center of rotation behavior of the lumbar spine with ligament failure," J. Neurosurg Spine, vol. 18, pp. 617-626, 2013.

[4] A. Tsouknidas, N. Michailidis, S. Savvakis, K. Anagnostidis, K. Bouzakis and G. Kapetanos, "A finite element model technique to determine the mechanical response of a lumbar spine segment under complex loads," J. Applied Biomechanics., vol. 28, pp. 448-456, 2012.

[5] A. Shrazi-Adl, "On the fibre composite material models of disc annulus-comparison of predicted stresses" $J$. Biomechanics., vol. 22, no. 4, pp. 357-365, 1989.

[6] D. Erbulut, I. Zafarparandeh, C. Hassan, I. Lazoglu and A. Ozer, "Determination of the biomechanical effect of an interspinous process device on implanted and adjacent lumbar spinal segments using a hybrid testing protocol: a finite-element study," J. Neurosurgery., vol. 23, no. 2, pp. 1-9, 2015.

[7] S. Kumerasan, N. Yoganandan, F. A. Pintar, "Finite element analysis of the cervical spine: a material property sensitivity study," Clinical Biomechanics., vol. 14, pp. 41-53, 1999.

[8] S. Naserkhaki, N. Arjmand, A. Shirazi-Adl, F. Farahmand and M. El-Rich, "Effects of eight different ligament property datasets on biomechanics of a lumbar L4-L5 finite element model,” J. Biomechanics., vol. 70, pp. 1-9, 2017. 